Commentary

\title{
Advanced Therapy Medicinal Products: What's in a Name?
}

\author{
Wim Jiskoot \\ Division of BioTherapeutics, Leiden Academic Centre for Drug Research, Leiden University, Leiden, the Netherlands \\ Coriolis Pharma, Martinsried, Germany
}

\section{A R T I C L E I N F O}

\section{Article history:}

Received 3 August 2020

Revised 23 August 2020

Accepted 24 August 2020

Available online 29 August 2020

\section{Keywords:}

Advanced therapy medicinal products

(ATMPs)

Cell-based medicinal products

Cell therapy

Gene therapy

Medicines

Terminology

Wording

\begin{abstract}
A B S T R A C T
In this commentary I briefly discuss the term advanced therapy medicinal products (ATMPs). The last two words, medicinal products, correctly indicate that we are dealing with medicines. However, oftentimes ATMPs and products within the ATMP family are erroneously called therapies, which may raise confusion, as illustrated with some examples, and may lead to ignorance of the importance of pharmaceutical product quality. The first two words, advanced therapy, are arguable as well, because they do not accurately describe the products involved and advanced is a temporal description of therapies, many of which may not (yet) be advanced at all. It is recommended to avoid such confusing wording and instead call medicines by their proper name.
\end{abstract}

(C) 2020 American Pharmacists Association ${ }^{\circledR}$. Published by Elsevier Inc. All rights reserved.

\section{Introduction}

According to the European Medicines Agency (EMA) website, advanced therapy medicinal products (ATMPs) are medicines for human use that are based on genes, tissues or cells, offering groundbreaking new opportunities for the treatment of disease and injury. ${ }^{1}$ The current ATMP family consists of four categories: gene therapy medicines, somatic cell therapy medicines, tissue engineered medicines and combined ATMPs (e.g., cells embedded in a biodegradable matrix or scaffold). ${ }^{1}$ Apart from these categories, the term cell-based medicinal products (CBMPs) is conveniently used for those ATMPs that are based on cells. ${ }^{2}$ These can be nongenetically modified somatic cells (i.e., somatic cell therapy medicines) or genetically modified cells (also called ex vivo gene therapy medicines, a subcategory within gene therapy medicines). The different ATMP categories are schematically summarized in Fig. 1. Definitions as well as examples of specific products within the respective ATMP categories can be found elsewhere. ${ }^{3-5}$

\section{Medicinal Products are Not Therapies}

Very few people would call a painkiller a headache therapy. This makes sense because the term therapy is synonymous with (medical) treatment, as one can find in any English dictionary.

E-mail address: w.jiskoot@lacdr.leidenuniv.nl (W. Jiskoot).
Remarkably, however, in the ATMP field the term therapy, or therapies, is increasingly used interchangeably with medicinal prod$u c t(s)$ : the use of therapies, immunotherapies, cell therapies, gene therapies and advanced therapies, when medicinal products are actually meant, is spreading like a pandemic virus in the scientific literature, at conferences and on (company) websites. To illustrate this, I discuss a few arbitrarily chosen examples of a tip of a vast iceberg of such erroneous language.

Let us consider the following quotes: "Addressing the challenges of preservation of cell and gene therapies" 6 and "Preservation of cell-based immunotherapies for clinical trials". ${ }^{7}$ For those who are less familiar with the field: preservation is commonly used within the ATMP field when we would perhaps use the word stabilization or storage (differences in terminology between the classical pharmaceutical biotech field and the ATMP field have been briefly discussed elsewehere ${ }^{5}$ ). Whereas preservation of therapies may be challenging for medical doctors, what is meant above are the challenges with storage or stabilization of medicinal products, which primarily should be a concern for pharmacists and pharmaceutical scientists.

How about "the manufacture of such [cell and gene] therapies" and "biopreservation of cell and gene therapies" ${ }^{8}$ Medical actions are, as far as I know, not manufactured; and it is not therapies that are biopreserved (whatever that means), but medicines to be used for these therapies. It may become even more confusing when we read about "the freezing of cell therapies" 8 and "cryopreservation of cellular therapies". ${ }^{9}$ Such phrases could be understood as (deep-)freezing the 


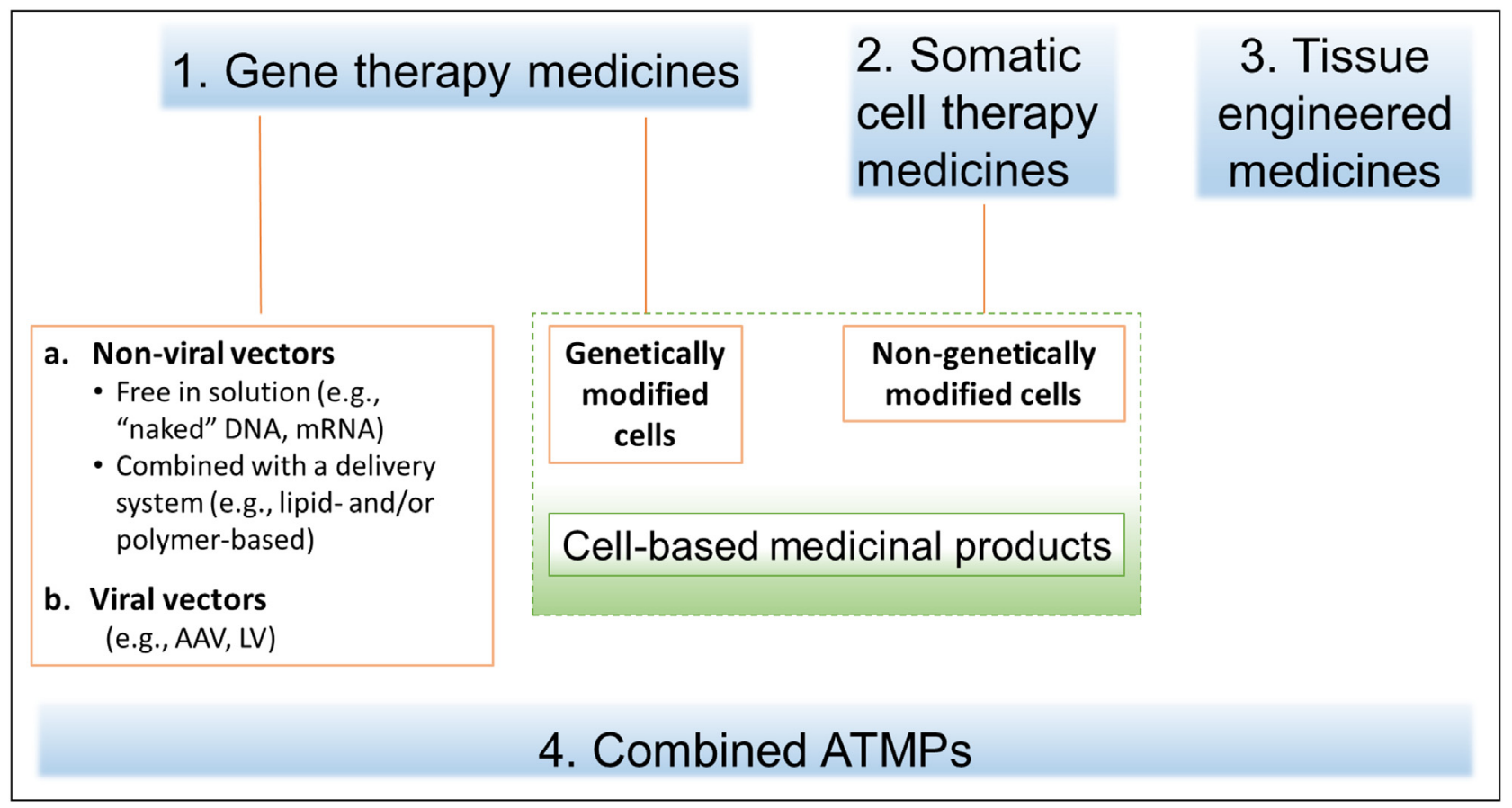

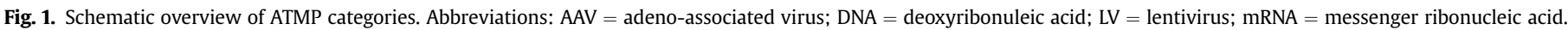

therapies, which may be interpreted as stopping or interrupting them, an entirely different meaning than the intended one.

One can also read about "submissions for mesenchymal stem cell therapies" and "market approval of an ex vivo gene therapy in Europe". However, regulatory agencies such as EMA do not approve therapies but medicines.

\section{How Advanced is Advanced?}

The term advanced in ATMPs is also debatable. In my opinion, the opposite may be true: most of the therapies that are making use of ATMPs are far from being advanced and rather in their infancy, just like ATMP formulations. ${ }^{5}$ Dose, dosing schedule, number of doses, etc., are in most cases not fully optimized. This is due to the many challenges we are still facing in the development of ATMPs and associated therapies. The therapies may be innovative, so innovative therapy medicinal products would perhaps be a more accurate term. However, just like advanced, innovative is a temporal description that is prone to becoming out of date as time proceeds. So, let's call a spade a spade, i.e., call things what they truly are.

\section{Concluding Remarks}

Therapies and medicinal products are mistakenly used synonymously. We should not forget that we administer medicines to patients, not therapies. Even in the case of autologous ATMPs, where therapy and medicinal product may seem to touch each other, the therapy only starts when the manufactured medicinal product is administered to the patient. The collection of a patient's material to be converted into a medicinal product by extensive manipulation (e.g., in case of somatic cell therapy products) and/or genetic modification (e.g., in case of ex vivo gene therapy products) is part of the manufacturing process of the product. Nevertheless, the term medicinal products threatens to be overruled by therapies, which not only is a linguistic flaw but also may lead to ignorance of the importance of pharmaceutical product quality. As pharmaceutical scientists we should know better and, while minding our profession, mind our words. The use of therapies should be reserved for treatments, which may or may not involve the use of (a) medicinal product(s). Gene therapy, for instance, can be performed by using a medicinal product based on an adeno-associated virus, an adenovirus, a lentivirus, naked DNA, DNA complexed with lipid nanoparticles, CAR-T cells, etc. (cf. Fig. 1). Using the term gene therapies for all these different physical and chemical forms of delivery of a gene could lead to confusion. For example, if one of these approaches has severe adverse effects it could limit development of other gene therapy medicines. This, in fact, may have already happened with the Jesse Gelsinger death caused by an immune response against an adenoviral vector for gene therapy. ${ }^{10}$ This may have hampered the gene therapy field in general, because the terminology was linked to all these other forms of gene delivery. A similar negative impact on all cell therapies could happen due to negative results with a certain specific sub-set of cell-based medicinal products if that were to occur.

ATMP is a regulatory term which rightly bears the noun product and is unlikely to change name soon. Nonetheless, it is good practice to specify which type of ATMP one refers to when talking about specific medicinal products (cf. Fig. 1), because the term ATMPs does not accurately describe the products involved. Moreover, what is advanced today may be routine or obsolete tomorrow: "nothing endures but change", as the Greek philosopher Heraclitus already knew about 2500 years ago. The more successful we are in moving the field of ATMPs and ATMP-based therapies forward, the earlier these products as well as the therapies for which they are intended may become truly advanced; while the A in ATMP eventually will stand for Archaic.

\section{References}

1. European Medicines Agency. Advanced therapy medicinal products: overview. https://www.ema.europa.eu/en/human-regulatory/overview/advancedtherapy-medicinal-products-overview. Accessed August 1, 2020.

2. European Medicines Agency. Guideline on human cell-based medicinal products. https://www.ema.europa.eu/en/documents/scientific-guideline/guideline-humancell-based-medicinal-products_en.pdf. Accessed August 1, 2020. 
3. Hoogendoorn KH. Advanced therapies: clinical, non-clinical and quality considerations. In: Crommelin DJA, Sindelar RD, Meibohm B, eds. Pharmaceutical Biotechnology. fifth ed. Cham, Switzerland: Springer International Publishing; 2019:357-402.

4.. Crommelin DJA, Mastrobattista E, Hawe A, Hoogendoorn KH, Jiskoot W. Shifting paradigms revisited: biotechnology and the pharmaceutical sciences. J Pharm Sci. 2020;109:30-43.

5. Hoogendoorn KH, Crommelin DJA, Jiskoot W. Formulation of cell-baded medicinal products: a matter of life or death? J Pharm Sci. 2020. https://doi.org/ 10.1016/j.xphs.2020.07.002.

6. Anonymous. Addressing thechallenges of preservation of cell and gene therapies https://insights.bio/cell-and-gene-therapy-insights/addressing-the-challengesof-preservation-of-cell-and-gene-therapies/. Accessed August 1, 2020.
7. Li R, Johnson R, Yu G, McKenna DH, Hubel A. Preservation of cell-based immunotherapies for clinical trials. Cytotherapy. 2019;21:943-957.

8. Rafiq QA, Nienow AW, Hewitt CJ, Coopman K. The role of biopreservation in cell and gene therapy bioprocessing. Cell Gene Therapy Insights. 2017;3(5):335344.

9. Anonymous. Understanding cryopreservation of cellular therapies. https://www. contractpharma.com/csd/profile/centre-for-commercialization-of-regenerativemedic/view_understanding-cryopreservation-of-cellular-therapies/. Accessed August 1, 2020.

10. Rinde M. The death of Jesse Gelsinger, 20 years later. https://www.sciencehistory. org/distillations/the-death-of-jesse-gelsinger-20-years-later. Accessed August 1 2020. 